\title{
COMMENTARY
}

\section{'Effective inefficiency': cellular control of protein trafficking as a mechanism of post-translational regulation}

\author{
P Michael Conn ${ }^{1,2,3}$, Jo Ann Janovick1, Shaun P Brothers ${ }^{1,2}$ and Paul E Knollman ${ }^{1}$ \\ ${ }^{1}$ Divisions of Neuroscience and Reproductive Sciences, Oregon National Primate Research Center and ${ }^{2}$ Departments of Physiology and Pharmacology and \\ ${ }^{3}$ Cell and Developmental Biology, Oregon Health and Science University, 505 NW 185th Ave., Beaverton, OR 97006, USA \\ (Requests for offprints should be addressed to P M Conn; Email: connm@ohsu.edu)
}

\begin{abstract}
The great writer and polyglot, W Somerset Maugham said, 'I'll give you my opinion of the human race in a nutshell...their heart's in the right place, but their head is a thoroughly inefficient organ.' If his words are applied to trafficking of the human pituitary gonadotropin-releasing hormone receptor, it turns out that he was more right than he knew. Paradoxically, the inefficiency of receptor trafficking to
\end{abstract}

the plasma membrane can bring regulatory advantages to cells. Understanding the mechanism by which cells recognize correctly folded proteins in health and disease opens doors to new therapeutic approaches and provides a more accurate view of mechanisms of normal cell function than is presently available.

Journal of Endocrinology (2006) 190, 13-16

\section{Misfolding of protein mutants in disease}

Often, mutant proteins lose function in cells. Loss of activity frequently results from misfolding but, until recently, it was believed to be solely explained by loss of protein function Mutations were viewed to cause loss of receptor-ligand binding (or effector coupling) or loss of substrate binding by enzymes, for example. Frequently, however, misfolded proteins are identified as defective by the cell's quality control system (QCS) and are retained by the endoplasmic reticulum (ER) for proteasomal destruction or for reprocessing, rather than trafficked to the normal site associated with function. This change in thinking - that mutants are often misrouted yet otherwise competent proteins - is a striking counterpoise to the former view that non-functioning mutants always have an intrinsic defect in the ability to perform. This newer view (Ulloa-Aguirre et al. 2003, 2004a, Castro-Fernandez et al. 2005, Conn \& Janovick 2005) acknowledges that the criteria for recognition of misfolded proteins by the cellular QCS is purely physical and does not always consider the ability of a protein to function. This is true because the chaperones of the QCS recognize general errors of folding, such as exposure of hydrophobic regions in an aqueous environment, rather than specific defects of individual proteins, such as failure of receptors to recognize ligands.

This observation also presents the possibility that mutants can be restored to function by pharmacological chaperones ('pharmacoperones'), small molecules that enter the cell and rescue misfolded mutants by promoting correct folding, allowing them to pass the QCS and become correctly routed (Conn et al. 2002, Janovick et al. 2002, 2003a, Leaños-Miranda et al. 2002).

\section{Misfolding and retention of GnRHR in normal cell function}

Recent observations (Knollman et al. 2005, Janovick et al. 2006) suggest that cells also use the technique of misfolding and misrouting as an effective post-translational regulatory mechanism to decrease the efficiency of movement of wild type (WT) proteins to their normal site of function and potentially provides a protein reserve to call upon when needed and without the need for transcription or translation. In this model, a WT receptor is delicately balanced between expression at the plasma membrane and retention in the ER. Consequently, even modest mutations can tip this balance and have a dramatic effect on plasma membrane expression. Accordingly, these rodent receptors that interfere with human gonadotropin-releasing hormone receptor (GnRHR) plasma membrane expression frequently do not have any impact on rat or mouse GnRHR, since, although about $90 \%$ homologous, these rodent mutants traffic to the plasma membrane with much higher efficiency than the human counterpart. 
It was surprising to find that there is a strong and convergent pressure for what initially appears to be a wasteful process in light of the high metabolic cost of this form of regulation. Intentionally destroying a potentially functional protein is a curious regulatory approach; proteins regulated in this manner must be created to be delicately balanced between function (plasma membrane) and destruction (ER). The observed convergent evolution suggests that the advantages of this process outweigh the disadvantages.

\section{Convergent evolution of decreased efficiency of expression of the GnRHR at the plasma membrane}

\section{Nature's experiments on GnRHRs - premammals}

Evidence (Lin et al. 1998, Janovick et al. 2003b) from comparing premammals (fish, reptiles, and birds) with the mammalian class and the primate order suggests that there is an ever-decreasing net efficiency of expression and maintenance of the GnRHR as the complexity of reproduction has increased. In premammalian groups, a long carboxyl terminal tail on the molecule (Fig. 1) is associated with high expression, since it not only acts to route the structure to the membrane, but also to diminish the rate of turnover. These animals produce large numbers of offspring (or eggs) at a low metabolic cost per unit, with relatively low survival. In contrast, in light of the greater 'per unit' cost and time needed to produce mammalian offspring, it is not surprising that this latter process would be regulated more precisely.

As mammals put more metabolic energy into the production of small numbers of offspring, the GnRHR solidifies a role as an analog-to-digital converter, integrating brain signals into a response of gonadotropin release. Levels of the mammalian GnRHR are well known to fluctuate cyclically and in rapid response to specific stimuli.

Among mammals, the observation that rat and mouse GnRHRs are highly expressed at the plasma membrane, while a smaller proportion of the synthesized human GnRHRs reach the plasma membrane, attracted our attention.

\section{Nature's experiments on GnRHRs - rats versus mice}

Despite its small size, nature has performed many experiments on the GnRHR. A good example of this is the difference between rat and mouse GnRHR. Even though these species are closely related, they differ in routing and in the dominantnegative (DN) effect, whereby a co-expressed mutant receptor causes WT receptor to be retained in the ER (Leaños-Miranda et al. 2003, 2005 Brothers et al. 2004, Knollman et al. 2005).

The difference in both routing and the DN effect appears to be mediated primarily by $\operatorname{Ser}^{216}$ in the rat GnRHR $\left(\mathrm{Gly}^{216}\right.$ in the mouse). These studies (Knollman et al. 2005) establish the relation between the DN effect and altered receptor trafficking and reveal that a change as modest as gain or loss of $-\mathrm{CH}_{2}-\mathrm{OH}$ (i.e. the chemical difference between Gly and Ser) can dramatically alter routing.

\section{Nature's experiments on GnRHRs - within mammals}

Compared with other G-protein coupled receptors (GPCR), the GnRHR is relatively small in mammals -327 amino acids in rats and mice, and 328 in most other mammals. This minimalist structure is the result of the absence of the extensive extracellular amino and carboxyl terminals found in other members of this super-family. The carboxyl terminal quite literally terminates in the plasma membrane and does not extend into the intracellular space as is common for other GPCRs.

There appears yet another difference, however. An 'extra' amino acid is inserted at position 191 in all mammalian GnRHRs cloned to date except rats and mice. This extra amino acid explains why rats and mice have 327 and other mammals have 328 amino acids. Removal of this 'extra' amino acid from the human sequence results in a dramatic increase in plasma membrane expression.

We came to realize (Janovick et al. 2006) that in primates, Lys ${ }^{191}$ (Glu ${ }^{191}$ in most other mammals) is part of a complex motif that, taken as whole, results in decreased efficiency of expression (Conn et al. 2002, Janovick et al. 2002, Ulloa-Aguirre et al. 2004b, Castro-Fernandez et al. 2005). This evolutionary progression that resulted in progressively diminished plasma membrane expression was intriguing and suggested an explanation of the ability of pharmacoperones to increase the expression of human (partially expressed) but not rat (more fully expressed) $\mathrm{GnRH}$ receptors at the plasma membrane.

The observation of agents which promoted the folding of the human GnRHR (hGnRHR) into a shape that passed the cellular QCS suggested that there was a percentage of receptors that were not initially destined to be expressed at the plasma membrane. The presence of the 'extra' amino acid in position 191 apparently decreased the efficiency of formation of a specific Cys bridge (Janovick et al. 2006) required for the human GnRHR to pass the cellular QCS. The consideration that there existed WT human GnRHR that were actually misfolded proteins was curious, since it meant that the cell was 'intentionally' synthesizing misfolded receptors - ones that would cost metabolic energy to make, but would not be used!

$\mathrm{Glu}^{191}$ is less effective than the primate Lys ${ }^{191}$ in decreasing plasma membrane GnRHR expression, another observation showing the progressive restriction of plasma membrane expression (Knollman et al. 2005).

The observation then is that nature is progressively decreasing the percentage of the GnRHR expressed at the plasma membrane as the complexity of the reproductive process increases. This approach costs energy, since not all the synthesized receptor is actually used. Nonetheless, there must be a selective advantage, since nature is effecting a solution to an as-yet unclear problem from different and functionally converging directions. 


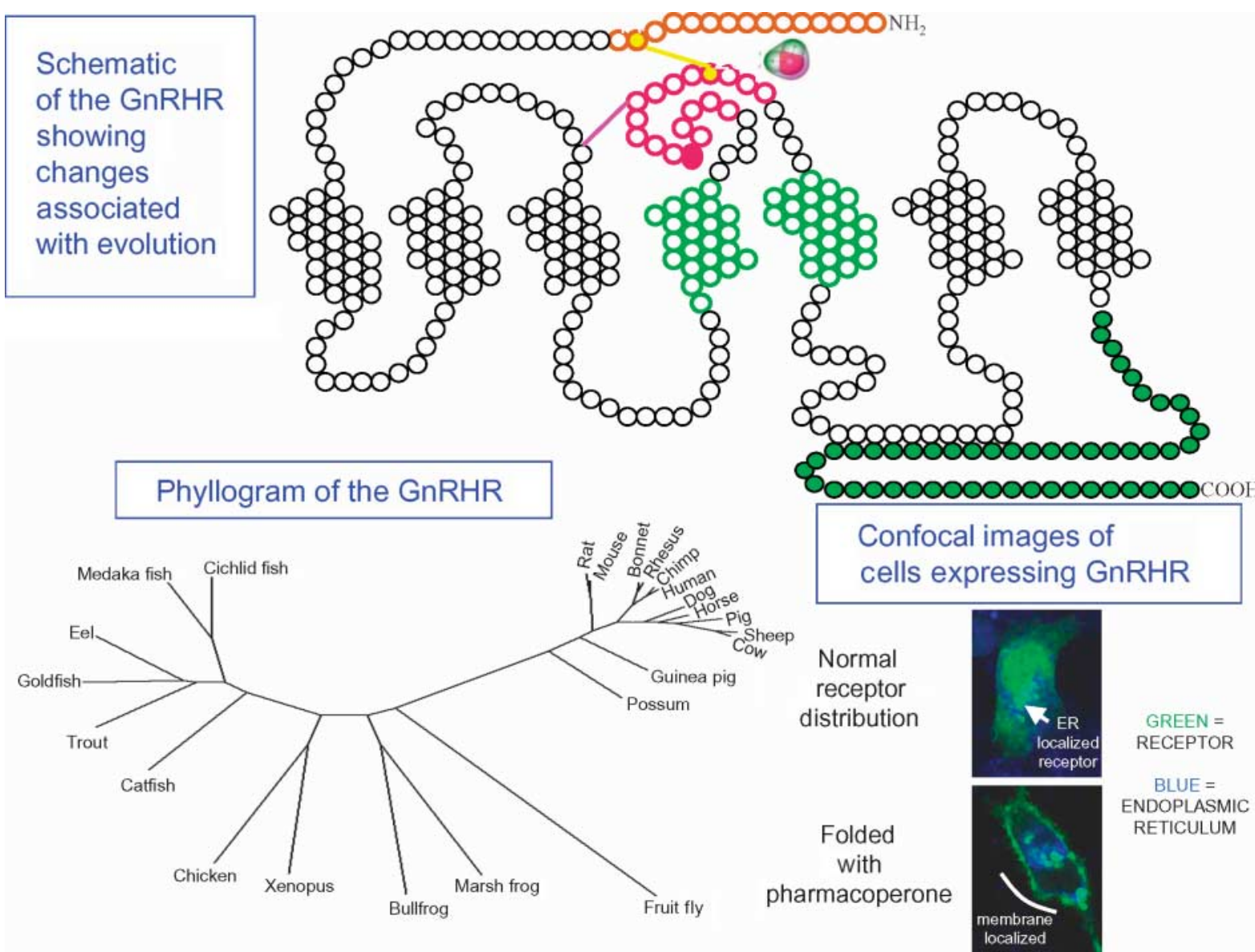

Figure $1 \mathrm{GnRHR}$ schematic, summarizing features that regulate plasma membrane expression. Circles represent amino acids. The image shows the carboxyl tail (solid green circles) present in birds, fish, and reptiles but lost in mammals. The solid red circle shows position 191 that frequently contains a Glu ${ }^{191}$ in mammals but is replaced by Lys ${ }^{191}$ in primates; in rats and mice this amino acid is absent. Two Cys-Cys bridges are shown. The Cys ${ }^{14}-\mathrm{Cys}^{200}$ (yellow) association must form for proper routing to the plasma membrane in most mammals and it is formalized by a covalent bond in primates; the formation of this association is destabilized by Glu ${ }^{191}$ (many mammals) or Lys ${ }^{191}$ (primates). Precise alignment of the cysteines (less than one water molecule (shown) in spacing) is regulated by alignment of the amino terminal (brown outline) with the second extracellular loops (ECL2, red outline). Twisting of the fourth and fifth transmembrane segments (green outline) controls the positioning of ECL2 and mutations in these regions (TMS4 and 5) and are frequently among the relatively rare unrescuable mutants. The graphic at the bottom is a phyllogram of the evolutionary relations between a wide diversity of species. The confocal images are cells expressing a fluorescent chimera of WT GnRHR (green). Normally, receptor is present at the plasma membrane and in the ER (stained blue); in the presence of pharmacoperone, its level at the plasma membrane is enhanced.

\section{Nature's experiments on GnRHRs - the primate receptor}

Nearly 200 mutants and 2 years after we began the search, we learned the basis of the complex motif involved in restricting expression of the hGnRHR - an unusual motif of nonsequential amino acids that enabled Lys ${ }^{191}$ to destabilize the Cys $^{14}-$ Cys $^{200}$ bridge in the hGnRHR required for correct folding - and produce a percentage of misfolded, and hence, misrouted receptors (Janovick et al. 2006).

\section{What is the advantage?}

It is clear that nature is using multiple approaches to restrict expression of GnRHR concurrent with increased reproductive complexity and metabolic investment per offspring. One feature of mammals is the occurrence of cyclicity of the GnRHR (Savoy-Moore et al. 1980, Marian et al. 1981) and the ability to regulate trafficking to the plasma membrane may provide the selective advantage that explains the advantage of this process. The ability to control the presence of a key integrator of the reproductive process without the need to synthesize it de novo allows the animal to optimize the time of reproduction, thus minimizing waste of a fertilized egg and protecting a costly investment indeed. Until the precise mechanism becomes clear, this is hypothetical, of course.

\section{Other proteins use a similar process}

Other receptors appear to show inefficient plasma membrane expression and misfolding frequently causes misrouting as well, 
even if mediated by alternate means (Castro-Fernandez et al. 2005). The human $\delta$ opioid receptor is an example, since permeable agonists and antagonists also facilitate posttranslational processing and increased export of the ligandstabilized receptor from the ER to the cell surface (Petäjä-Repo et al. 2002). Other reports indicate that other receptors (GluR1, alpha $\mathrm{D}_{1} \mathrm{D}$ adrenoreceptor, odorant, and $\mathrm{LH}$ receptors) are likewise inefficiently expressed at the plasma membrane (Saito et al. 2004, Uberti et al. 2004, Petrovska et al. 2005, Pietila et al. 2005), and this suggests that restricted trafficking may be a more commonly occurring means of regulating protein availability than is presently appreciated.

\section{Conclusions}

Nature has left a clear trail, progressively diminishing the expression of the GnRHR with increased complexity and cost/unit of production of offspring. This inefficiency has been an effective mechanism for exerting tighter control on the reproductive process. The observation that other proteins, receptors, ion channels, and enzymes, are not fully expressed at their normal locus of action suggests that this mechanism of post-translational regulation may be a common event.

\section{Acknowledgements}

The authors congratulate the Society for Endocrinology on the occasion of their Diamond Jubilee. This work was supported by NIH grants HD-19899, RR-00163, TW/HD00668 and HD-18185.

\section{References}

Brothers SP, Cornea A, Janovick JA \& Conn PM 2004 Human 'loss-offunction' gonadotropin releasing hormone receptor mutants retain wildtype receptors in the endoplasmic reticulum: basis of the dominant-negative effect. Molecular Endocrinology 18 1787-1797.

Castro-Fernandez C, Maya-Nunez G \& Conn PM 2005 Beyond the signal sequence: protein routing in health and disease. Endocrine Reviews 26 479-503.

Conn PM \& Janovick JA 2005 A new understanding of protein mutation unfolds. American Scientist 93 314-321.

Conn PM, Leaños-Miranda A \& Janovick JA 2002 Protein origami: therapeutic rescue of misfolded gene products. Molecular Interventions 2 308-316.

Janovick JA, Maya-Nuñez G \& Conn PM 2002 Rescue of hypogonadotropic hypogonadism-causing and manufactured $\mathrm{GnRH}$ receptor mutants by a specific protein-folding template: misrouted proteins as a novel disease etiology and therapeutic target. Journal of Clinical Endocrinology and Metabolism 87 3255-3262.

Janovick JA, Goulet M, Bush E, Greer J, Wettlauffer D \& Conn PM 2003a Structure-activity relations of successful pharmacologic chaperones for rescue of naturally occurring and manufactured mutants of the gonadotropin-releasing hormone receptor. Journal of Pharmacology and Experimental Therapeutics 305 608-614.

Janovick JA, Ulloa-Aguirre A \& Conn PM 2003b Evolved regulation of gonadotropin releasing hormone receptor plasma membrane expression. Endocrine 22 317-328.
Janovick JA, Knollman PE, Brothers SP, Ayala-Yáñez R, Aziz AS \& Conn PM 2006 Regulation of $\mathrm{G}$ protein coupled receptor trafficking by inefficient plasma membrane expression: molecular basis of an evolved strategy. Journal of Biological Chemistry 281 8417-8425.

Knollman PE, Janovick JA, Brothers SP \& Conn PM 2005 Parallel regulation of membrane trafficking and dominant-negative effects by misrouted GnRH receptor mutants. Journal of Biological Chemistry 280 24506-24514.

Leaños-Miranda A, Janovick JA \& Conn PM 2002 Receptor-misrouting: an unexpectedly prevalent and rescuable etiology in GnRHR-mediated hypogonadotropic hypogonadism. Journal of Clinical Endocrinology and Metabolism 87 4825-4828.

Leaños-Miranda A, Ulloa Aguirre A, Ji TH, Janovick JA \& Conn PM 2003 Dominant-negative action of disease-causing GnRHR-mutants: a trait that potentially co-evolved with decreased plasma membrane expression of GnRHR in humans. Journal of Clinical Endocrinology and Metabolism $\mathbf{8 8}$ 3360-3367.

Leaños-Miranda A, Ulloa-Aguirre A, Janovick JA \& Conn PM 2005 In vitro coexpression and pharmacological rescue of mutant $\mathrm{GnRH}$ receptors causing hypogonadotropic hypogonadism in humans expressing compound heterozygous alleles. Journal of Clinical Endocrinology and Metabolism 90 3001-3008.

Lin X, Janovick JA, Brothers SP, Blomenröhr J, Bogerd J \& Conn PM 1998 Addition of catfish gonadotropin-releasing hormone $(\mathrm{GnRH})$ receptor intracellular carboxyl-terminal tail to rat $\mathrm{GnRH}$ receptor alters receptor expression and regulation. Molecular Endocrinology 12 161-171.

Marian J, Cooper RL \& Conn PM 1981 Regulation of the rat pituitary gonadotropin-releasing hormone receptor. Molecular Pharmacology 19 399-405.

Petäjä-Repo UE, Hogue M, Ghalla S, Laperrière A, Morello JP \& Bouvier M 2002 Ligands act as pharmacological chaperones and increase the efficiency of $\delta$ opioid receptor maturation. EMBO Journal 21 1628-1637.

Petrovska R, Kapa I, Klovins J, Schioth HB \& Uhlen S 2005 Addition of a signal peptide sequence to the alpha(1D) adrenoceptor gene increases the density of receptors, as determined by $[(3) \mathrm{H}]$-prazosin binding in the membranes. British Journal of Pharmacology 144 651-659.

Pietila EM, Tuusa JT, Apaja PM, Aatsinki JT, Hakalahti AE, Rajaniemi HJ \& Petaja-Repo UE 2005 Inefficient maturation of the rat luteinizing hormone receptor, A putative way to regulate receptor numbers at the cell surface. Journal of Biological Chemistry $28026622-26629$.

Saito H, Kubota M, Roberts RW, Chi Q \& Matsunami H 2004 TRP family members induce functional expression of mammalian odorant receptors. Cell 119 679-691.

Savoy-Moore RT, Schwartz NG, Duncan JA \& Marshall JC 1980 Pituitary gonadotropin-releasing hormone receptors during the rat estrous cycle. Science 209 942-944.

Uberti MA, Hague C, Oller H, Minneman KP \& Hall RA 2004 Heterodimerization with beta-2-adrenergic receptors promotes surface expression and functional activity of alpha-1D-adrenergic receptors. Journal of Pharmacology and Experimental Therapeutics 313 16-23.

Ulloa-Aguirre A, Janovick JA, Leanos-Miranda A \& Conn PM 2003 Surface receptors as a novel disease etiology and potential therapeutic target: the case of hypogonadotropic hypogonadism due to gonadotropin-releasing hormone resistance. Expert Opinion on Therapeutic Targets 7 175-185.

Ulloa-Aguirre A, Janovick JA, Leaños-Miranda A \& Conn PM 2004a Misrouted cell surface gonadotropin-releasing hormone receptors as a common disease etiology of congenital isolated hypogonadotropic hypogonadism. Human Reproduction Update 10 177-192.

Ulloa-Aguirre A, Janovick JA, Brothers SP \& Conn PM $2004 b$ Pharmacological rescue of conformationally-defective proteins: implications for the treatment of human disease. Traffic 5 821-837.

Received 13 March 2006

Accepted 17 March 2006

Made available online as an Accepted Preprint 24 March 2006 